\title{
Correction: Editorial zur Ausgabe „Depression und Suizidalität“"
}

\author{
Alexandra Ramssl-Sauer
}

Online publiziert: 8. April 2020

(c) Springer-Verlag GmbH Austria, part of Springer Nature 2020

\section{Correction:}

Psychotherapie Forum (2019) 23:79-80

https://doi.org/10.1007/s00729-019-00129-x

Der Artikel Editorial zur Ausgabe „Depression und Suizidalität“ von Alexandra Ramssl-Sauer wurde ursprünglich am 20. Dezember 2019 mit „Open Access“ online auf der Internetplattform des Verlags publiziert. Die Autorin hat sich jedoch nachträglich gegen eine „Open Access“-Veröffentlichung entschieden. Das Urheberrecht des Artikels wurde deshalb im April 2020 in (C) Springer-Verlag GmbH Austria, ein Teil von Springer Nature 2020 geändert. Der Artikel wird nun unter diesem Copyright veröffentlicht. 